\title{
The pathophysiological changes associated with neonatal death of cloned pigs
}

\author{
Zheng $\mathrm{Ao}^{1,2,3, *}$, Ting $\mathrm{Gu}^{1,3, *}$, Huaxing Zhao ${ }^{1,3}$, Junsong Shi ${ }^{4}$, Enqin Zheng ${ }^{1,3}$, Gengyuan Cai ${ }^{1,3}$, \\ Zhenfang $\mathrm{Wu}^{1,3}$ and Zicong $\mathrm{Li}^{1,3}$ \\ ${ }^{1}$ National Engineering Research Center for Breeding Swine Industry, College of Animal Science, South China \\ Agricultural University, Guangzhou, China, ${ }^{2}$ Key Laboratory of Animal Genetics, Breeding and Reproduction in the \\ Plateau Mountainous Region, Ministry of Education, College of Animal Science, Guizhou University, Guizhou, \\ China, ${ }^{3}$ Guangdong Provincial Key Laboratory of Agro-animal Genomics and Molecular Breeding, College of Animal \\ Science, South China Agricultural University, Guangdong, China and ${ }^{4}$ Wen's Research Institute, Guangdong Wen's \\ Foodstuff Group, Ltd., Guangdong, China
}

Correspondence should be addressed to Z Wu or Z Li; Email: wzfemail@163.com or lizicong@scau.edu.cn

\begin{abstract}
Cloned pigs generated by the somatic cell transfer nuclear (SCNT) technique are highly valuable for agriculture, biomedicine, and life sciences. However, the neonatal mortality rate of cloned pigs is very high. The reasons causing the massive loss of cloned pigs during their neonatal ages are unclear. In the present study, we found that the neonatal death of cloned pigs was associated with aberrant purine metabolism, impaired renal morphology and function, and decreased hepatic Hprt1 expression. The downregulation of $H$ prt1, a key purine metabolism regulation gene, in the liver was responsible for the elevation of an important purine metabolite, uric acid, in the serum, causing abnormalities in kidney morphology and function and leading to death of neonatal cloned pigs. This study provided insights into the pathophysiological mechanisms underlying the neonatal death of clone pigs, and results will help improve their survival rate.

Reproduction (2020) 160 193-203
\end{abstract}

\section{Introduction}

Cloned pigs, especially genetically modified cloned pigs that are generated by the somatic cell transfer nuclear (SCNT) technique, are highly valuable to the swine industry, biomedicine, and life sciences (Yang \& Wu 2018). However, the neonatal death rate of cloned piglets is extremely high, which reaches $47.8-74.5 \%$ (Jiang et al. 2008, Kurome et al. 2013, Huan et al. 2015, Schmidt et al. 2015). The neonatal death of cloned pigs mainly occurs within 4 days after birth (Ao et al. 2017). Most of the cloned piglets that died shortly after birth had various malformations (Jiang et al. 2008, Park et al. 2010, Schmidt et al. 2015). The massive loss of cloned pigs during neonatal age severely limits their application. The mechanisms underlying the high mortality rate of neonatal cloned pigs remain unknown.

Serum contains a wide range of metabolites involved in numerous biochemical and biophysiological processes in the animal body (Psychogios et al. 2011). Analysis of dynamic alteration of serum metabolic profiling has become an important approach in monitoring the state of biological organisms and elucidates the physiological and pathological mechanisms related to various diseases (Zhang et al. 2012, Mussap et al. 2013, Yi et al. 2016). Currently, metabolomics is a powerful tool for exploring global metabolite changes in biological systems by analyzing the metabolites with regard to various exposures or disease states (Johnson et al. 2016). Metabolomics analysis is particularly important in neonatal and pediatric studies for the early diagnosis and identification of a variety of neonatal complications, such as intrauterine growth retardation (IUGR) (Marincola et al. 2015), inborn errors of metabolism (Vernon 2015), perinatal asphyxia (Ahearne et al. 2016), kidney disease (Noto et al. 2016), and bronchopulmonary dysplasia (Rivera et al. 2016).

To investigate the pathophysiological mechanisms underlying the high neonatal death rate of cloned pigs, we compared the serum metabolomic differences among dead SCNT-derived, survived SCNT-derived, and survived artificial insemination (Al)-produced neonatal pigs, and explored the possible causes of neonatal loss of cloned pigs. We found that neonatally deceased cloned pigs exhibited abnormal purine metabolism and impaired renal morphology and function, which might be caused by decreased expression of hepatic Hprt1. 


\section{Materials and methods}

\section{Ethics statement}

All animal procedures used in this study were conducted in accordance with "The Instructive Notions with Respect to Caring for Laboratory Animals," issued by the Ministry of Science and Technology of China and were approved by the Institutional Animal Care and Use Committee of South China Agricultural University (Animal protocol approval number: 2017K006). All efforts were made to minimize animal suffering.

\section{Serum sample collection and preparation}

SCNT-derived and Al-derived pigs were produced as described in a previous study (Ao et al. 2017). The semen used for Al and the donor cells used for SCNT were derived from a same Duroc boar. SCNT recipient sows and artificially inseminated sows were raised at a same pig farm under the same conditions. All the piglets were delivered by spontaneous farrowing at around 114 days of gestation. After birth, the piglets were dried by towel immediately and placed in an incubator with temperature of $30^{\circ} \mathrm{C}$ for $1 \mathrm{~h}$, and then they were assisted to suck colostrum. Piglets were injected intramuscularly with $200 \mathrm{mg}$ iron dextran at $24 \mathrm{~h}$ after birth to prevent anemia. At delivery, piglets are held firmly by an assistant to prevent umbilical cord rupture. Umbilical cord was bound with a numbered sterile thread to distinguish the placenta of each piglet. After expulsion of the placentas, the attached amniotic membrane, necrotic tips of avascularized chorion, and umbilical cord on placenta were removed. Then, placental weight and surface area were measured using a previously described method (Baxter et al. 2008). Fresh blood was collected from the anterior vein of live piglet at $36 \mathrm{~h}$ after birth. Anterior vein serum was prepared from blood by centrifugation at 1,600 $\mathrm{g}$ for $15 \mathrm{~min}$ and were immediately snap-frozen in liquid nitrogen and stored at $-80^{\circ} \mathrm{C}$. Survival and morbidity status of each piglet were consistently tracked and recorded every hour after blood collection. Piglets were divided into three groups according to their survival and morbidity status at 4 days after birth, as follows: the SCNT-derived male piglets that died within 4 days (SCNT-DW4); SCNT-derived male piglets that survived over 4 days (SCNT-SO4); and Al-generated male piglets that survived over 4 days (AI-SO4). Renal and liver tissues were immediately collected from the dead SCNT-DW4 piglets and the terminated AI-SO4 piglets at 4 days after birth.

Prior to metabolomics analysis, all serum samples were thawed at $4{ }^{\circ} \mathrm{C}$, and each serum sample $(200 \mu \mathrm{L})$ was added to a $1.5 \mathrm{~mL}$ Eppendorf tube with $10 \mu \mathrm{L}$ of 2 -chloro-l-phenylalanine $(0.3 \mathrm{mg} / \mathrm{mL})$ dissolved in methanol as the internal standard, and the tube was vortexed for $10 \mathrm{~s}$. Subsequently, the samples were mixed with $240 \mu \mathrm{L}$ ice-cold mixture of methanol and acetonitrile (2/1, v/v), vortexed, and centrifuged $(13,000$ g, $\left.15 \mathrm{~min}, 4^{\circ} \mathrm{C}\right)$. The supernatants $(200 \mu \mathrm{L})$ from each tube were collected using crystal syringes, filtered through 0.22 $\mu \mathrm{m}$ microfilters, and transferred to liquid chromatography (LC) vials. The vials were stored at $-80^{\circ} \mathrm{C}$ until LC-mass spectrometry (LC-MS) analysis. Quality control (QC) samples were prepared by mixing aliquots of the all samples to create the pooled sample.

\section{LC-MS/MS analysis}

The prepared samples were analyzed by an ACQUITY ultraperformance liquid chromatography (UPLC) I-Class system (Waters Corp., Milford, USA) coupled with QTOF Mass spectrometer (Waters Corp.) following the manufacturer's instructions. An ACQUITY UPLC BEH C18 column (100 $\mathrm{mm} \times 2.1 \mathrm{~mm}, 1.7 \mu \mathrm{m})$ maintained at $45{ }^{\circ} \mathrm{C}$ was used for the reversed phase separation with a mobile phase $\mathrm{A}(0.1 \%$ formic acid in water) and B (0.1\% formic acid in acetonitrile) under the following elution gradient: $0 \mathrm{~min}, 1 \% \mathrm{~B} ; 1 \mathrm{~min}, 30 \%$ B; $2.5 \mathrm{~min}, 60 \% \mathrm{~B} ; 6.5 \mathrm{~min}, 90 \% \mathrm{~B} ; 8.5 \mathrm{~min}, 100 \% \mathrm{~B} ; 10.7$ $\min , 100 \% \mathrm{~B} ; 10.8 \mathrm{~min}, 1 \% \mathrm{~B}$ and $13 \mathrm{~min}, 1 \% \mathrm{~B}$. The flow rate was $0.4 \mathrm{~mL} / \mathrm{min}$, and the injection volume per sample was $2 \mu \mathrm{L}$. The autosampler temperature was set at $4^{\circ} \mathrm{C}$. A high-resolution tandem mass spectrometer Xevo G2-XS QToF (Waters Corp.) was used to detect the compounds eluted from the column using electrospray ionization (ESI) in both positive and negative modes. Data acquisition was performed in full scan mode $(\mathrm{m} / \mathrm{z}$ ranges from 50 to $1000 \mathrm{Da})$ with a scanning time of $0.1 \mathrm{~s}$. The optimized conditions of QTOF/MS were as follows: capillary voltage, $3 \mathrm{kV} /-2 \mathrm{kV}$; source temperature, $120^{\circ} \mathrm{C}$; sampling cone, $40 \mathrm{~V}$; and cone gas flow, $50 \mathrm{~L} / \mathrm{h}$. The desolvation temperature and flow rate were $450^{\circ} \mathrm{C}$ and 800 $\mathrm{L} / \mathrm{h}$, respectively. The mean square error (MSE) model was selected for acquisition. The lower collision energy was $6 \mathrm{~V}$, and the higher collision ramp energy was 20-35 V. During the acquisition, the leucine-enkephalin (LE) signal was acquired every $3 \mathrm{~s}$ to calibrate the mass accuracy. Furthermore, QC sample (from the pool of all samples) was injected after every eight samples to evaluate the stability of the LC-MS during the entire acquisition.

\section{Data processing and metabolite identification}

The acquired LC-MS raw data were analyzed by the Progenesis QI 2.3 software (Waters) for data processing. Data pretreatment of raw UPLC-MS data included peak picking, peak grouping, retention time (RT) correction, second peak grouping, and annotation of isotopes and adducts. The Excel file was obtained with three-dimensional data sets, including $\mathrm{m} / \mathrm{z}$, peak RT, peak intensities, and RT-m/z pairs, which were used as the identifier for each ion. The resulting matrix was further reduced by removing peaks with more than $80 \%$ missing values (ion intensity $=0$ ) and those with isotope ions from each group. The adduct ion forms, including $\left[\mathrm{M}+\mathrm{H}-2 \mathrm{H}_{2} \mathrm{O}\right]^{+},[\mathrm{M}+\mathrm{H}]^{+},[\mathrm{M}+\mathrm{K}]^{+}$, $[\mathrm{M}+\mathrm{Na}]^{+},\left[\mathrm{M}+\mathrm{HH}_{4}\right]^{+},[2 \mathrm{M}+\mathrm{H}]+,\left[2 \mathrm{M}+\mathrm{NH}_{4}\right]^{+},[2 \mathrm{M}+\mathrm{Na}]^{+}$, and $[2 \mathrm{M}+\mathrm{k}]^{+}$in the positive ion mode and $\left[\mathrm{M}-\mathrm{H}_{2} \mathrm{O}-\mathrm{H}\right]^{-},[\mathrm{M}-\mathrm{H}]^{-}$, $[2 \mathrm{M}-\mathrm{H}]^{-}$, and $[2 \mathrm{M}+\mathrm{FA}-\mathrm{H}]^{-}$in the negative ion mode, were selected based on their ionization behaviors. Each retained peak was normalized to the QC sample using robust Loess signal correction. A threshold of $40 \%$, which was accepted as a standard in the assessment of repeatability in metabolomics data sets, was set for the relative standard deviation values of metabolites in the QC samples. The resulting data were imported into SIMCA 14.0 software (Umetrics, Sweden). Principle component analysis (PCA) and partial least-squaresdiscriminant analysis (PLS-DA) were carried out to visualize the metabolic alterations among the experimental groups 
after mean centering (Ctr) and Pareto variance (Par) scaling, respectively. The reliability of the models was assessed with the relevant $R^{2}$ and $Q^{2}$. The performance of the PLS-DA models was evaluated using permutation testing (200 permutations). The variable influence on projection (VIP) from the PLS-DA model with values $>1.0$ was set as the threshold for selecting statistically significant metabolites. Then, $t$-test and fold change (FC) analysis were performed to measure the significance of metabolic features from the preprocessed UPLC-MS datasets. Our screening requirement for differential metabolites was FC $>1.2$ or $<0.8333, P$ value $<0.05$ and VIP $>1.0$. Afterward, Human Metabolome Databases (HMDB) (http://www.hmdb. $\mathrm{ca} /$ ) and the Lipid Maps Database (http://www.lipidmaps. org/tools/) were used for serum metabolite identification. A combination of database queries was performed using the exact molecular masses and fragmentation traits.

\section{Serum biochemical analysis}

Serum uric acid, creatinine, and urea nitrogen levels were analyzed by HITACHI 7020 automatic chemistry analyzer (Hitachi). Test reagent kits were used according to the manufacturer's instructions (Kehua, Shanghai, China).

\section{Enzymatic determination in serum}

Hypoxanthine phosphoribosyltransferase 1 (HPRT1) and phosphoribosyl pyrophosphate synthetase 1 (PRPS1) levels in the serum samples were measured using commercially available enzyme immunoassay kits (Jianglai, Shanghai, China) according to the manufacturer's instructions.

\section{Histopathological analysis of kidney}

The renal tissues were fixed with $4 \%$ paraformaldehyde and was embedded in paraffin for histological analysis. The embedded sections were stained with hematoxylin \& eosin (HE) based on standard histological procedures (Hong et al. 2014). The morphological changes in the renal tissue were observed using a Nikon 80i light microscope (200× magnification) fitted with a Nikon (DS-Fi1) digital camera (Nikon).

\section{Quantitative real-time PCR}

Total RNA was extracted from liver tissues using Total RNA Kit (Omega Bio-tek, GA, USA). The cDNA was synthesized from $1 \mu \mathrm{g}$ of total RNA using the PrimeScript RT Reagent Kit (Takara). Quantitative real-time PCR was performed using the SYBR Select Master Mix Kit (Thermo Fisher Scientific) and QuantStudio $^{\text {TM }} 7$ Flex Real-Time PCR System (Thermo Fisher Scientific). Primer information for target genes is presented in Table 1. Each reaction mixture $(10 \mu \mathrm{L})$ contained $1 \mu \mathrm{L}$ of the cDNA solution, $0.3 \mu \mathrm{L}$ of $10 \mathrm{mM}$ of each specific primer, $5 \mu \mathrm{L}$ of SYBR Select Master Mix, and $3.4 \mu \mathrm{L}$ of $\mathrm{ddH}_{2} \mathrm{O}$. The reactions were run as follows: initial denaturation at $95^{\circ} \mathrm{C}$ for $5 \mathrm{~min} ; 40$ cycles of denaturation at $95^{\circ} \mathrm{C}$ for $10 \mathrm{~s}$; annealing at $60^{\circ} \mathrm{C}$ for $15 \mathrm{~s}$ with an extension at $72^{\circ} \mathrm{C}$ for $20 \mathrm{~s}$; and finally, a melting cycle consisting of $95^{\circ} \mathrm{C}$ for $15 \mathrm{~s}, 55^{\circ} \mathrm{C}$ for $15 \mathrm{~s}$, and $60^{\circ} \mathrm{C}$ for $15 \mathrm{~s}$. The relative expression levels of target genes were calculated with $2^{-\Delta \Delta C t}$ method and normalized to $\beta$-Actin. All gene expression experiments were conducted in triplicate. Each pair of primers was confirmed for equal amplification efficiency for serial dilutions of cDNA sample in accordance to a previously reported method (Dhanasekaran et al. 2010).

\section{DNA preparation and DNA methylation measurements}

Genomic DNA was extracted from liver tissues using the DNA extraction kit (Bio-tek Corporation, Beijing, China) according to the manufacturer's instruction. A Nanodrop 2000 spectrophotometer (Thermo Fisher Scientific) was used to measure DNA concentration of each liver sample. The CpG island of the promoter region (between -1500 and +1000 bp from transcription start site, chromosome X:110319704110322204) was analyzed through the website (http://www. ebi.ac.uk/Tools/seqstats/emboss_cpgplot/) (Fig. 6A). Then, the upstream and downstream primers for quantitative methylation analysis were designed by using the EpiDesigner (Agena Bioscience, San Diego, CA, USA). The primer information was as follows: forward, 5' - TTTTTTTTGTGGTTTTAAATTGGG-3' and reverse, 5'-AAATAAAAAACAATTAAATATTCCCC

TC-3'. Quantitative methylation analysis was performed using the MassARRAY platform (Agena Bioscience, San Diego, CA, USA), which relies on uracil-specific cleavage followed by matrix-assisted laser desorption/ionization-time of flight-mass spectrometer (MALDI-TOF-MS). Genomic DNA was treated by $\mathrm{NaHSO}_{3}$ (Zymo, Orange, CA, USA) through the following reactions: PCR amplification $\left(94^{\circ} \mathrm{C}\right.$ for $4 \mathrm{~min} ; 45$ cycles of $94^{\circ} \mathrm{C}$ for $20 \mathrm{~s}, 56^{\circ} \mathrm{C}$ for $30 \mathrm{~s}$, and $72^{\circ} \mathrm{C}$ for $1 \mathrm{~min}$; then $72^{\circ} \mathrm{C}$ for $3 \mathrm{~min})$; shrimp alkaline phosphatase (SAP) reaction $\left(37^{\circ} \mathrm{C}\right.$ for $20 \mathrm{~min}, 85^{\circ} \mathrm{C}$ for $\left.5 \mathrm{~min}\right)$; and finally base specific cleavage reaction $\left(37^{\circ} \mathrm{C}\right.$ for $\left.3 \mathrm{~h}\right)$. Subsequently, the resins were used to purify the abovementioned products that were then spotted

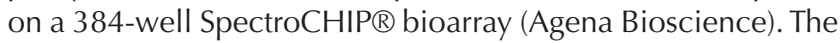
SpectroCHIP were analyzed using MassARRAY system, and methylation levels of each CpG site were obtained using the EpiTYPER software (Agena Bioscience).

\section{Statistical analyses}

The differences in birth weight, placental traits, serum biochemical indexes, serum enzymatic levels, mRNA

Table 1 Primers used for qPCR.

\begin{tabular}{|c|c|c|c|c|}
\hline \multirow[b]{2}{*}{ Genes } & \multicolumn{2}{|c|}{ Primer sequences $\left(5^{\prime}\right.$ to $\left.3^{\prime}\right)$} & \multirow[b]{2}{*}{ Product size $(b p)$} & \multirow[b]{2}{*}{ GenBank accession no. } \\
\hline & Forward & Reverse & & \\
\hline Hprt1 & CCCAGCGTCGTGATTAGTGATG & CAAGCCGTTCAGTCCTGTCCAT & 133 & NM_001032376 \\
\hline Prps 1 & CCGATGCTGGAGGAGCTAAGAG & TCCGTGAGTCAGGATTGCGTAA & 245 & XM_003135301 \\
\hline Actb & CСACGAGACСАССТTСААСТС & TGATСТССТTСТGСАTССТGT & 131 & DQ8445171 \\
\hline
\end{tabular}


expression levels, and methylation levels among the different groups were statistically analyzed by one-way ANOVA using the SPSS 19.0 software (IBM Corp.). All data are presented as mean \pm S.E.M.. Significant difference of means between two different groups was determined at $P<0.05$.

\section{Results}

Differences in malformation rate, neonatal survival rate, birth weight, and placental parameters between SCNT and AI piglets

We obtained $12 \mathrm{Al}$-derived male piglets farrowed by 3 sows and 18 SCNT-derived male piglets delivered from 5 recipient sows (Table 2 ). All 12 Al piglets survived over 4 days (SO4) after birth. Among the 18 cloned piglets, 12 died within 4 days (DW4) after birth, and 6 survived over 4 days after birth. No malformation was observed in all $12 \mathrm{Al}$ piglets, but phenotypic malformations, such as macroglossia, umbilical hernia, limb hyperflexion, hypoplastic testis, were found in 7 newborn SCNT piglets, which all died within 4 days after birth (Table 2). The birth weight, placental surface area, placental weight, and placental efficiency were similar between $\mathrm{AI}-\mathrm{SO} 4$ and SCNT-SO4 piglets, but these developmental indexes were significantly higher in $\mathrm{Al}-\mathrm{SO} 4$ and SCNT-SO4 piglets than in SCNT-DW4 piglets (Table 3).

\section{Differences in serum metabolite profiles among SCNT-DW4, SCNT-SO4 and Al-SO4 piglets}

As shown in Supplementary Figs 1 and 2 (see section on supplementary data given at the end of this article), the total ion chromatograms (TIC) and PCA score plot of QC samples revealed that the chromatographic separation had acceptable stability and reproducibility. A total of 15,588 ions (9586 in positive and 6002 in negative ion mode) were selected for the subsequent screening process. The PCA and PLS-DA score plots of acquired normalized data showed that the SCNT-SO4 group was closer to the AI-SO4 group than to the SCNT-DW4 group (Fig. 1). This suggested that the SCNT-SO4 and Al-SO4 groups had a more similar serum metabolite profile compared with the SCNT-DW4 group. The PLS-DA model demonstrated a more explicit separation among the three piglet groups than the PCA model (Fig. 1). Therefore, significantly different ions between SCNT-DW4 and AI-SO4 piglets and those between SCNT-DW4 and SCNT-SO4 piglets were analyzed by the PLS-DA model and subjected to subsequent analyses.
By comparing the exact ion masses and their fragmentation patterns with those from the HMDB and LipidMaps database, 95 and 68 differential serum metabolites were identified between SCNT-DW4 and AI-SO4 piglets, and between SCNT-DW4 and SCNT-SO4 piglets, respectively. Among them, 31 differential serum metabolites were common between $\mathrm{Al}-\mathrm{SO} 4$ and SCNT-SO4 piglets compared with SCNT-DW4 piglets (Table 4). Among these 31 common differential serum metabolites, 12 were upregulated and 19 were downregulated in SCNT-DW4 piglets, compared with SCNT-SO4 and AI-SO4 piglets (Table 4). Pathway analysis of the 31 common differential serum metabolites showed that three and two common differential serum metabolites were significantly enriched in the purine metabolism and the steroid hormone biosynthesis pathways, respectively (Fig. 2). The serum levels of all five common differential serum metabolites enriched in two pathways, including uric acid, xanthosine, deoxyinosine, cortol, and tetrahydrocortisone, were dramatically elevated in SCNT-DW4 piglets compared with those in SCNT-SO4 and $\mathrm{Al}-\mathrm{SO} 4$ piglets (the FC numbers are shown in Table 4). The abnormal steroid hormone biosynthesis found in SCNT-DW4 piglets could be related to the dysregulation of the expression of some steroid hormone biosynthesis enzyme genes in the placenta and the level of some steroid hormones in the amniotic fluid of cloned pig fetuses, as we previously reported (Ao et al. 2019). Therefore, we subsequently focused on exploring the causes of the aberrant purine metabolism in SCNT-DW4 piglets.

\section{Differences in serum uric acid, HPRT1, and PRPS1 levels among SCNT-DW4, SCNT-SO4 and Al-SO4 piglets}

Our serum biochemical analysis confirmed that the serum uric acid level of SCNT-DW4 piglets was significantly higher than those of Al-SO4 and SCNT-SO4 piglets ( Fig. 3). This was consistent with the metabolomic results shown in Table 4. Uric acid is a waste product of purine metabolism, which is regulated by two key enzymes encoded by Hprt1 and Prps 1 genes (Maiuolo et al. 2016). Downregulation of Hprt1 expression or upregulation of Prps 1 expression usually results in the elevation of serum uric acid level (Ahmed et al. 1999, CeballosPicot et al. 2009, Riches et al. 2009). Therefore, we measured the serum HPRT1 and PRPS1 enzyme levels to determine whether they are related to the serum uric acid level in three groups of piglets. Our results showed

Table 2 Comparison of malformation rate and neonatal survival rate between SCNT and AI piglets.

\begin{tabular}{|c|c|c|c|c|c|c|}
\hline \multirow[b]{2}{*}{ Group } & \multirow[b]{2}{*}{ Litters } & \multicolumn{3}{|c|}{ Piglets born } & \multirow[b]{2}{*}{ DW4/Malformed } & \multirow[b]{2}{*}{ SO4/Malformed } \\
\hline & & Total & Stillborn & Malformed & & \\
\hline $\mathrm{Al}$ & 3 & $12^{*}$ & 0 & 0 & $0 / 0$ & $12 / 0$ \\
\hline SCNT & 5 & 18 & 0 & 7 & $12 / 7$ & $6 / 0$ \\
\hline
\end{tabular}

*Only male fetuses from the AI group were used as sex-matched controls, because SCNT-derived fetuses were cloned from male donor cells. 
Table 3 Comparison of birth weight and placental parameters between SCNT and AI piglets.

\begin{tabular}{|c|c|c|c|}
\hline Item & $\begin{array}{l}\text { Al-SO4 } \\
(n=12)\end{array}$ & $\begin{array}{c}\text { SCNT-SO4 } \\
\quad(n=6)\end{array}$ & $\begin{array}{c}\text { SCNT-DW4 } \\
(n=12)\end{array}$ \\
\hline Birth weight (g) & $1702 \pm 240.3^{*}$ & $1793 \pm 338.4^{*}$ & $1316 \pm 199.5^{+}$ \\
\hline $\begin{array}{l}\text { Placental } \\
\text { weight (g) }\end{array}$ & $205.4 \pm 32.4^{*}$ & $212.2 \pm 28.3^{*}$ & $174.6 \pm 19.6^{\dagger}$ \\
\hline $\begin{array}{l}\text { Placental surface } \\
\text { area }\left(\mathrm{cm}^{2}\right)\end{array}$ & $2755 \pm 424.3^{*}$ & $2824 \pm 648.1^{*}$ & $1899 \pm 298.6^{\dagger}$ \\
\hline $\begin{array}{l}\text { Placental } \\
\text { efficiency }(g / g)^{\#}\end{array}$ & $8.34 \pm 0.76^{*}$ & $8.41 \pm 0.59^{*}$ & $7.53 \pm 0.76^{+}$ \\
\hline
\end{tabular}

${ }^{*},+$ Values labeled with different superscript symbols within the same row mean significant difference from one another at $P<0.05$.

"Placental efficiency $=$ birth weight/placental weight.

that SCNT-DW4 piglets had a significantly lower serum HPRT1 enzyme level than AI-SO4 piglets and an almost significantly lower $(P=0.069)$ serum HPRT1 enzyme level than SCNT-SO4 piglets but had a similar serum PRPS1 enzyme level with SCNT-SO4 and AI-SO4 piglets (Fig. 3). These results suggested that the increased serum uric acid level in SCNT-DW4 piglets was related to the lower serum HPRT1 enzyme level but not the serum PRPS1 enzyme level.
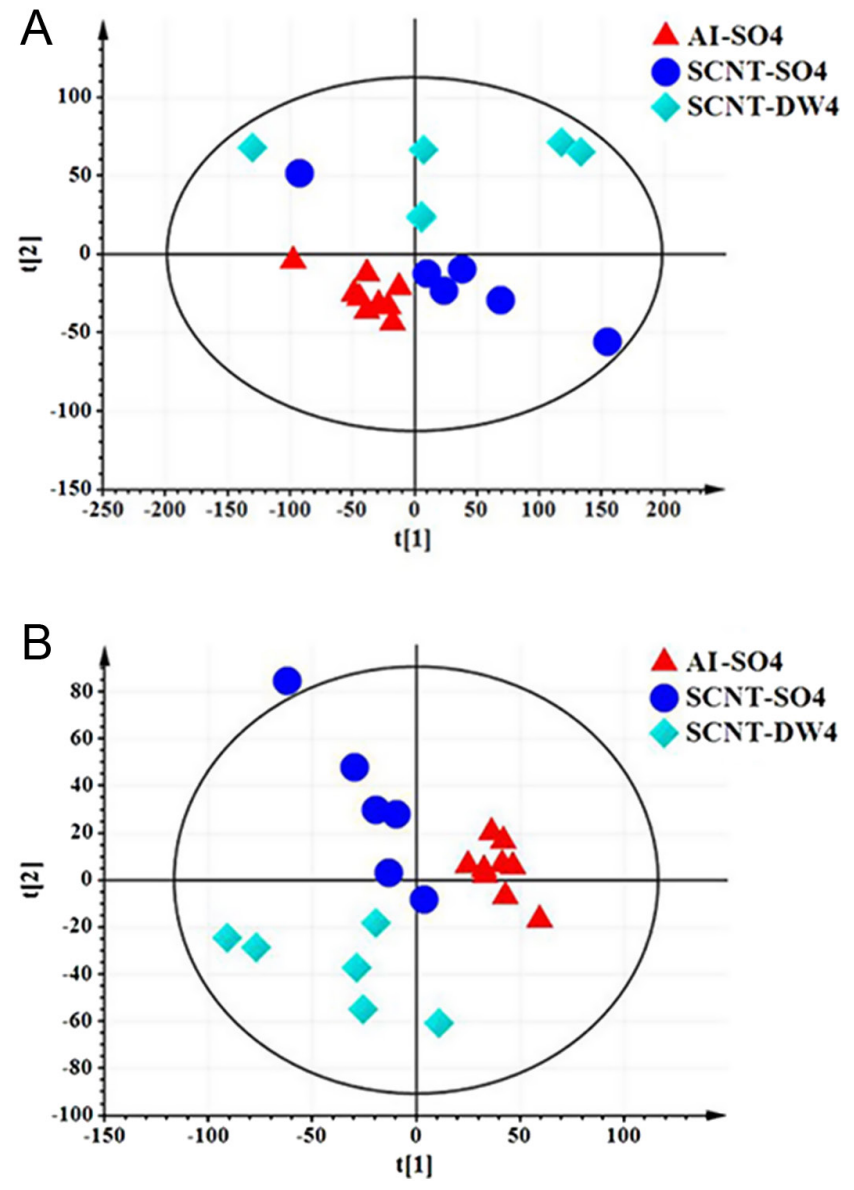

Figure 1 Multivariate analysis of the serum metabolic profiles of AI-SO4, SCNT-SO4, and SCNT-DW4 piglets. (A) PCA score plot. (B) PLS-DA score plot $(\mathrm{R} 2 \mathrm{X}=0.503, \mathrm{R} 2 \mathrm{Y}=0.89$, and $\mathrm{Q} 2=0.676)$.

\section{Differences in kidney function and morphology between AI-SO4 and SCNT-DW4 piglets}

Elevated uric acid level contributes to the development and progression of renal diseases (Siu et al. 2006, Hobbs et al. 2010, Kanbay et al. 2011). Therefore, we investigated whether the abnormal increase of serum uric acid level in SCNT-DW4 piglets impairs kidney function and morphology. We found that the serum levels of two clinical indices of renal function, namely creatinine and urea nitrogen, were significantly increased in SCNT-DW4 piglets compared with AI-SO4 piglets (Fig. 4A). Histopathological analysis also showed that kidney tissues from SCNT-DW4 piglets exhibited tubule abnormalities (Fig. 4B). These data suggested that the elevated serum level of uric acid caused injury to the kidney morphology and function of SCNT-DW4 piglets.

\section{Differences in hepatic Hprt1 and Prps1 mRNA levels between SCNT-DW4 and Al-SO4 piglets}

We measured the hepatic mRNA level of two key purine metabolism regulation genes, Hprt1 and Prps1, to see if they are related to the erroneously increased serum uric acid level in SCNT-DW4 piglets due to the fact that purine metabolism mainly occurs in the liver. The qPCR results showed that SCNT-DW4 piglets had a significantly lower hepatic Hprt1 transcript level than Al-SO4 piglets; yet, their hepatic Prps 1 mRNA abundance was similar to that of SCNT-DW4 piglets (Fig. 5). These results demonstrated that downregulation of Hprt1 transcription level in the liver tissue was associated with decreased serum HPRT1 level and elevated serum uric acid level in SCNT-DW4 piglets.

\section{Differences in hepatic Hprt1 gene promoter DNA methylation level between SCNT-DW4 and Al-SO4 piglets}

To investigate whether the decreased expression of Hprt1 gene in the liver of SCNT-DW4 piglets was linked to its promoter DNA methylation level, we subsequently determined the Hprt1 gene promoter DNA methylation degree in the liver tissues of Al-SO4 and SCNT-DW4 piglets. Our results indicated that $\mathrm{Al}-\mathrm{SO} 4$ and SCNT-DW4 piglets showed no difference in the average hepatic Hprt1 gene promoter DNA methylation level, but two piglets in the SCNT-DW4 group had a higher hepatic Hprt1 gene promoter DNA methylation level than the $\mathrm{Al}-\mathrm{SO} 4$ piglets (Fig. 6)

\section{Discussion}

We found that cloned piglets born with malformation, low birth weight, and low placental indexes, like those of SCNT-DW4 piglets, have an extremely high risk of dying during the neonatal age. These findings were 
Table 4 Common serum differential metabolites between AI-SO4 and SCNT-SO4 in comparison with SCNT-DW4 piglets.

\begin{tabular}{|c|c|c|c|c|c|c|c|}
\hline \multirow[b]{2}{*}{ Metabolites } & \multirow[b]{2}{*}{ Metabolic pathways } & \multicolumn{3}{|c|}{ SCNT-DW4/AI-SO4 } & \multicolumn{3}{|c|}{ SCNT-DW4/SCNT-SO4 } \\
\hline & & VIP & $P$ value & $\mathrm{FC}$ & VIP & $P$ value & $\mathrm{FC}$ \\
\hline Uric acid & Purine metabolism & 2.04 & 0.004 & 3.43 & 1.81 & 0.048 & 2.22 \\
\hline Xanthosine & Purine metabolism & 1.65 & 0.001 & 2.08 & 1.48 & 0.023 & 1.63 \\
\hline Deoxyinosine & Purine metabolism & 3.18 & 0.003 & 11.61 & 2.9 & 0.024 & 4.86 \\
\hline Cortol & Steroid hormone biosynthesis & 2.73 & 0.001 & 7.11 & 1.95 & 0.041 & 3.00 \\
\hline Tetrahydrocortisone & Steroid hormone biosynthesis & 2.31 & 0.001 & 3.98 & 1.94 & 0.015 & 2.33 \\
\hline Carnosine & Histidine metabolism & 1.61 & 0.001 & 1.97 & 1.27 & 0.032 & 1.46 \\
\hline L-Methionine & Methionine biosynthesis & 1.93 & 0.019 & 2.27 & 2.67 & 0.003 & 3.14 \\
\hline Glycolic acid & $\begin{array}{l}\text { Chlorocyclohexane and } \\
\text { chlorobenzene degradation }\end{array}$ & 2.37 & 0.033 & 9.48 & 2.67 & 0.044 & 9.03 \\
\hline Phosphoenolpyruvic acid & $\begin{array}{l}\text { Glycolysis/Gluconeogenesis; } \\
\text { Citrate cycle (TCA cycle) }\end{array}$ & 1.10 & 0.000 & 1.35 & 1.65 & 0.002 & 1.54 \\
\hline Aminoadipic acid & Lysine biosynthesis & 3.56 & 0.000 & 12.34 & 3.11 & 0.005 & 4.30 \\
\hline Linoleic acid & $\begin{array}{l}\text { Linoleic acid metabolism; } \\
\text { Biosynthesis of unsaturated } \\
\text { fatty acids }\end{array}$ & 1.27 & 0.014 & 0.66 & 1.74 & 0.007 & 0.60 \\
\hline Retinal & Retinol metabolism & 2.02 & 0.032 & 0.42 & 2.67 & 0.018 & 0.35 \\
\hline Arginyl-Histidine & Null & 1.11 & 0.037 & 0.70 & 2.33 & 0.001 & 0.45 \\
\hline Aspartyl-Glutamine & Null & 1.94 & 0.002 & 0.32 & 1.45 & 0.031 & 0.66 \\
\hline LysoPC(18:2(9Z,12Z)) & Null & 1.14 & 0.007 & 0.71 & 1.53 & 0.004 & 0.68 \\
\hline LysoPC $(18: 3(6 Z, 9 Z, 12 Z))$ & Null & 1.62 & 0.002 & 0.55 & 1.99 & 0.008 & 0.52 \\
\hline LysoPE $(0: 0 / 16: 0)$ & Null & 1.16 & 0.038 & 0.68 & 1.45 & 0.032 & 0.67 \\
\hline LysoPE(0:0/18:3(6Z,9Z,12Z)) & Null & 2.01 & 0.003 & 0.40 & 1.83 & 0.016 & 0.54 \\
\hline LysoPE(0:0/20:2(11Z,14Z)) & Null & 1.95 & 0.009 & 0.40 & 2.42 & 0.010 & 0.41 \\
\hline LysoPE(0:0/22:6(4Z,7Z,10Z,13Z,16Z,19Z)) & Null & 1.67 & 0.017 & 0.59 & 1.75 & 0.033 & 0.54 \\
\hline LysoPE(18:2(9Z,12Z)/0:0) & Null & 2.02 & 0.000 & 0.47 & 2.54 & 0.001 & 0.39 \\
\hline LysoPE(20:4(5Z,8Z,11Z,14Z)/0:0) & Null & 1.50 & 0.010 & 0.56 & 1.44 & 0.032 & 0.66 \\
\hline LysoSM(d18:1) & Null & 1.58 & 0.011 & 0.55 & 2.27 & 0.003 & 0.45 \\
\hline MG(15:0/0:0/0:0) & Null & 1.68 & 0.002 & 0.42 & 2.12 & 0.007 & 0.4 \\
\hline $\mathrm{PC}(17: 2(9 \mathrm{Z}, 12 \mathrm{Z}) / 0: 0)$ & Null & 1.06 & 0.030 & 0.73 & 1.50 & 0.011 & 0.67 \\
\hline PE(16:0/22:5(4Z,7Z,10Z,13Z,16Z)) & Null & 1.56 & 0.003 & 0.50 & 1.64 & 0.011 & 0.61 \\
\hline $\operatorname{PE}(10: 0 / 10: 0)$ & Null & 1.82 & 0.004 & 0.47 & 2.69 & 0.001 & 0.36 \\
\hline PS(12:0/15:1(9Z)) & Null & 1.55 & 0.010 & 0.47 & 2.78 & 0.008 & 0.24 \\
\hline PS(20:4(5Z,8Z,11Z,14Z)/0:0) & Null & 1.80 & 0.002 & 0.48 & 2.02 & 0.003 & 0.52 \\
\hline PC(18:3(9Z,12Z,15Z)/22:1(13Z)) & Null & 2.15 & 0.000 & 3.04 & 1.66 & 0.019 & 1.77 \\
\hline PS(19:0/20:2(11Z,14Z)) & Null & 2.17 & 0.010 & 4.45 & 2.57 & 0.015 & 4.47 \\
\hline
\end{tabular}

similar to those reported previously (Estrada et al. 2007, Schmidt et al. 2015, Ao et al. 2017). We further demonstrated that neonatally deceased cloned piglets exhibited abnormal purine metabolism at birth. Three purine metabolites, including uric acid, xanthosine and deoxyinosine, had a significant higher level in SCNT-DW4 piglets than in AI-SO4 and SCNT-SO4 piglets. This is the first study showing that purine metabolism problem is associated with the neonatal death of cloned piglets.

Under normal physiological conditions, the enzymes involved in purine metabolism can maintain the balance between the synthesis and degradation of purine nucleosides (Maiuolo et al. 2016). Uric acid is the end product of the metabolism of purine, which was proposed to be one of the major antioxidants of the plasma that prevent oxidative damage to cells (Sautin \& Johnson 2008). However, a high level of uric acid is a key risk factor for the pathogenesis of many diseases, such as gout (Maiuolo et al. 2016), hypertension (Perlstein et al. 2006), diabetes (Dehghan et al. 2008), and cardiovascular disease (Borghi et al. 2015).
Elevated uric acid is also relevant to the progression and development of nephropathy (Kang et al. 2002, Zhou et al. 2012, Ryu et al. 2013). Hyperuricemia rat models were subjected to severe renal dysfunction, including thickening of the preglomerular arteries with smooth muscle cell proliferation, renal hypertrophy, and glomerulosclerosis, which may be associated with

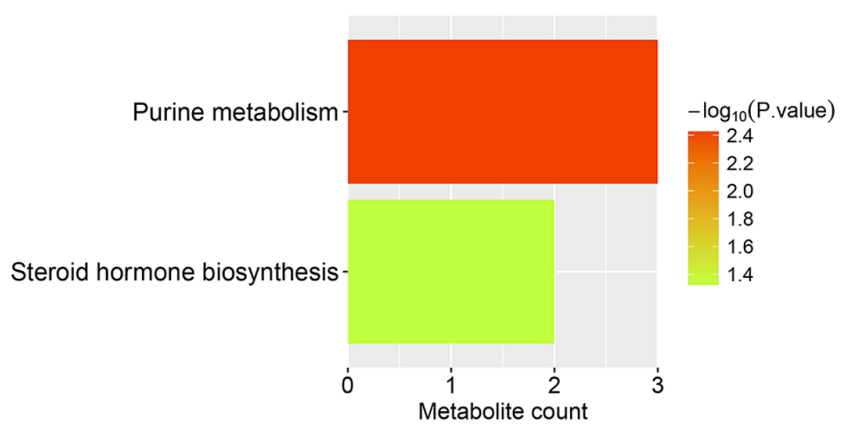

Figure 2 Pathway enrichment analysis of common serum differential metabolites between $\mathrm{Al}-\mathrm{SO} 4$ and SCNTSO 4 in comparison with SCNT-DW4 piglets. 


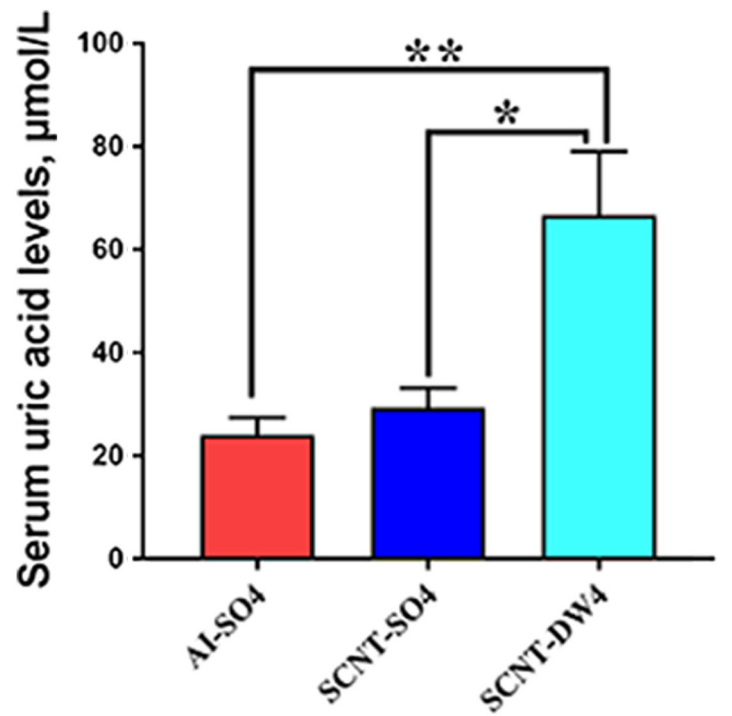

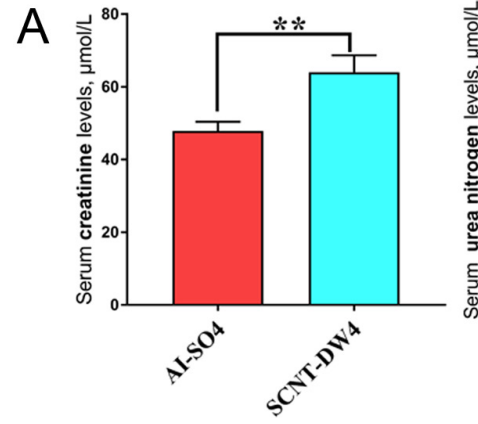

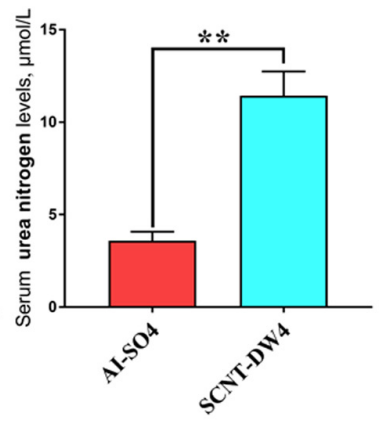

$B$
$\times$
$\stackrel{\bigcirc}{\circ}$
$\underset{ }{\mp}$

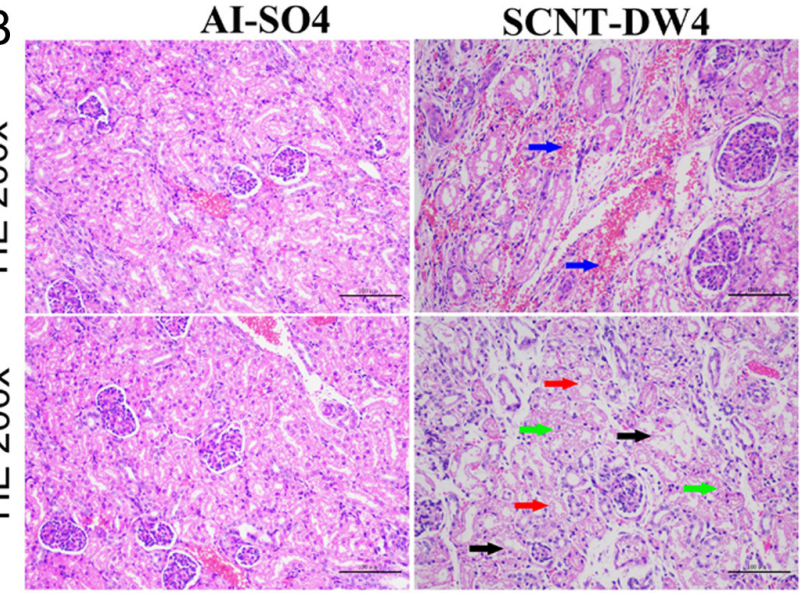

Figure 4 Comparison of renal function and morphology between Al-SO4 and SCNT-DW4 piglets. (A) Comparison of serum creatinine and urea nitrogen levels, which are two clinical indices for renal function, between AISO4 and SCNT-DW4 piglets. ${ }^{* *} P<0.01$. (B) Comparison of renal morphology between AI-SO4 and SCNTDW4 piglets by hematoxylin and eosin staining of kidney sections. The kidneys of SCNT-DW4 piglets exhibited several hemorrhagic foci (blue arrow), extensive edema of renal tubular epithelial cells (red arrow), cytoplasm loosening (green arrow), and partial tubular necrosis (black arrow), bar $=100 \mu \mathrm{m}$.

vascular disease linked to increased uric acid level (Kang et al. 2002). Hyperuricemia in experimental animals and humans leads to the worsening of proteinuria and renal failure along with associated
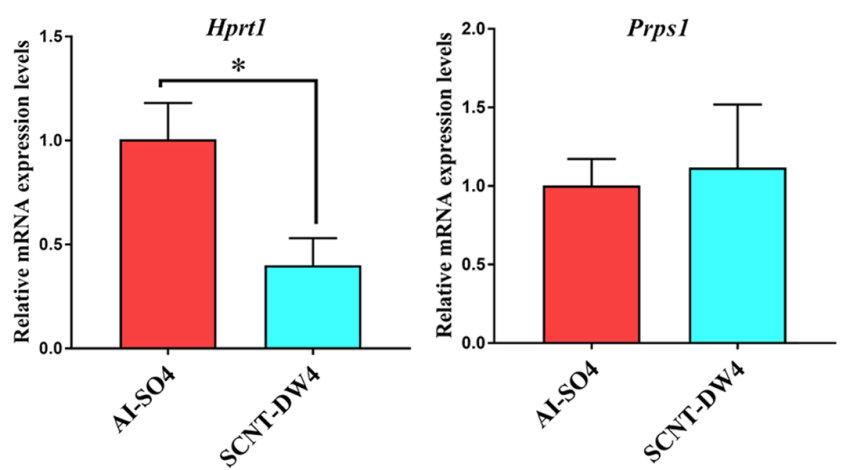

Figure 5 Comparison of Hprt1 and Prps1 mRNA expressions in the liver tissues of $\mathrm{Al}-\mathrm{SO} 4$ and SCNT-DW4 piglets. * means significant difference at $P<0.05$.
Figure 3 Comparison of serum uric acid, HPRT1, and PRPS1 levels among AI-SO4, SCNT-SO4, and SCNT-DW4 piglets. $*, \mathrm{P}<0.05 ; * *, \mathrm{P}<0.01$. 


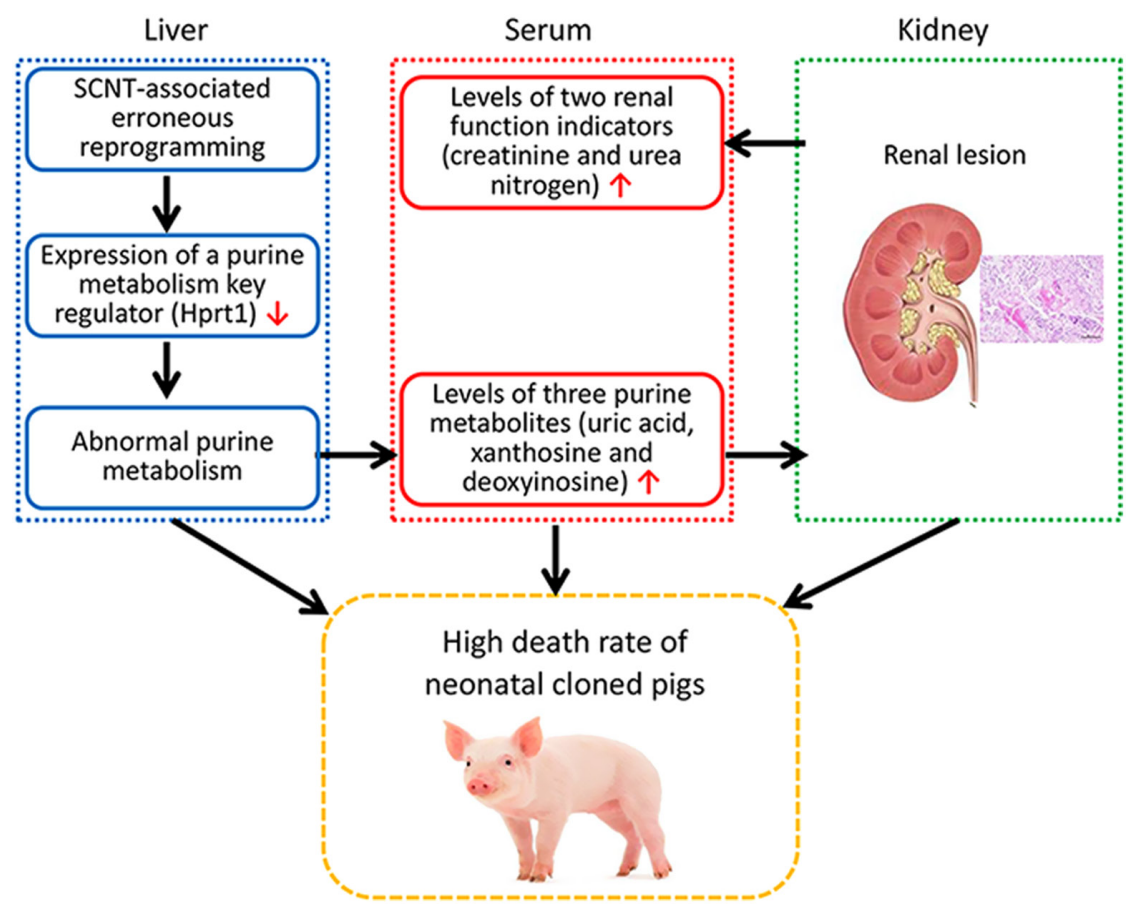

Kidney

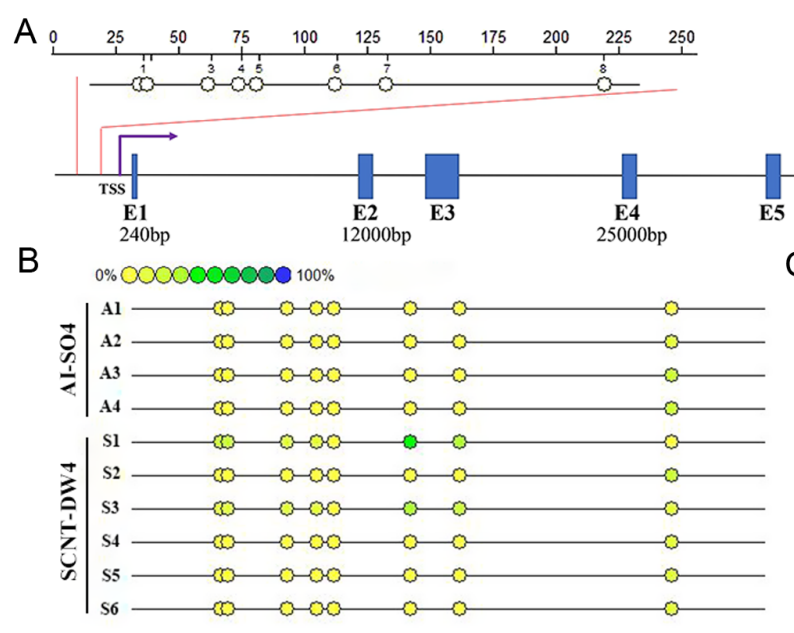

glomerular sclerosis and tubulointerstitial fibrosis found that SCNT-derived piglets were accompanied by some renal abnormalities, such as dilated renal pelvis, hydronephrosis, misshapen kidney, severe calcification, tubular degeneration and increased apoptosis (Park et al. 2009, Schmidt et al. 2015). Moreover, deceased neonatal cloned pigs were associated with diabetic nephropathy (Park et al. 2010). In this study, SCNT-DW4 piglets showed abnormal renal pathological characteristics, including extensive hydropic swelling and cytoplasmic rarefaction of tubular cells and partial tubular necrosis and significantly increased levels of serum creatinine SCNT-DW4 piglets had renal dysfunction. Uric acid could cause abnormal morphology and function of renal tubular cells by decreasing E-cadherin synthesis through
(Lapsia et al. 2012, Xu et al. 2017). Previous studies had and urea nitrogen. These results suggested that the

\begin{abstract}
Figure 6 Comparison of the Hprt1 promoter DNA methylation levels in the liver tissues of $\mathrm{Al}-\mathrm{SO} 4$ and SCNTDW4 piglets. (A) Diagram of the tested CpG units within the Hprt1 promoter. (B) Hepatic DNA methylation levels of the tested CpG sites within the Hprt1 promoter. Yellow and blue circle mean hypomethylation and hypermethylation, respectively. (C) Comparison of hepatic DNA methylation levels of the Hprt1 promoter between SCNT-DW4 and AI-SO4 piglets.
\end{abstract}

the activation of Snail and Slug and by enhancing the degradation of E-cadherin to induce the epithelial-tomesenchymal transition of renal tubular cells (Ryu et al. as a potential risk factor that contributes to the morbidity and mortality of neonatal cloned pigs.

Uric acid formation during purine catabolism is mainly catalyzed by an enzyme called HPRT1, which is an essential enzyme responsible for the metabolic salvage of purines in mammalian cells (Ceballos-Picot et al. 2009). SCNT-DW4 piglets had a lower serum HPRT1 level than AI-SO4 piglets. In humans, HPRT1 deficiency causes clinical disorders, such as Lesch-Nyhan disease (LND), which is characterized by the overproduction of uric acid and characteristic neurobehavioral abnormalities, including self-injurious behavior,

dystonia, and cognitive disability (Jinnah et al. 2006, 2013). Therefore, increased uric acid level might serve

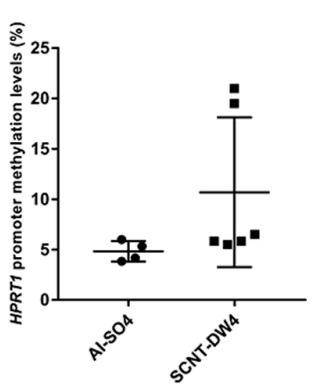

Figure 7 Schematic representation of a possible mechanism underlying neonatal death of cloned pigs by abnormal purine metabolism. Red downward and upward arrows represent decrease and increase, respectively. 
Ceballos-Picot et al. 2009). Some clinical case reports showed that patients with LND suffered from sudden and unexpected death (Neychev \& Jinnah 2006). Cloned pigs are likely to have neurological problems; sudden death is also a frequent phenomenon in cloned pigs (Park et al. 2005). The liver is the main organ that produces endogenous uric acid (Maiuolo et al. 2016). Hepatic Hprt1 mRNA expression level was significantly downregulated in SCNT-DW4 piglets, which is consistent with the findings of a previous study (Jiang et al. 2008). Thus, the reduced hepatic expression of Hprt1 may be responsible for the elevated uric acid level in SCNT-DW4 piglets.

Hprt1 is an X chromosome-linked gene. Aberrant expression of X-linked genes due to erroneous epigenetic reprogramming of donor cells have been found in cloned mammalian embryos (Jiang et al. 2008, Inoue et al. 2010, Ruan et al. 2018). Thus, the abnormal expression pattern of $X$-linked genes was likely to persist in cloned neonates (Jiang et al. 2008). The DNA methylation pattern is the main way by which to regulate gene expression (Cedar \& Bergman 2009). However, our results showed that there was no significant correlation between Hprt1 expression and promoter DNA methylation level, indicating that the reduced expression of Hprt1 may be regulated by other epigenetic modifications, such as histone modification, which were related to the erroneous gene expression and low developmental competence of cloned pig embryos or piglets (Yamanaka et al. 2009, Zhou et al. 2014, Cao et al. 2015, Xie et al. 2016).

Given that the increased serum uric acid level could be the cause of neonatal death of cloned pigs, reducing serum uric acid level may be an effective way to improve the survival rate of cloned pigs during the neonatal period. Several uric acid-reducing drugs have been clinically used to treat hyperuricemia. These medicines include Allopurinol (Yelken et al. 2012), Febuxostat (Kataoka et al. 2015) and Benzbromarone (Ogino et al. 2010). Therefore, treating newborn cloned piglets with these drugs in the future may be an attractive attempt to improve their neonatal survival rate.

In summary, as shown in Fig. 7, neonatally deceased cloned pigs displayed renal dysfunction and purine metabolism abnormalities, which might be caused by the SCNT-induced downregulation of hepatic Hprt1 expression.

\section{Supplementary materials}

This is linked to the online version of the paper at https://doi. org/10.1530/REP-20-0143.

\section{Declaration of interest}

The authors declare that there is no conflict of interest that could be perceived as prejudicing the impartiality of the research reported.

\section{Funding}

This work was supported by one grant from the National Transgenic Major Projects of China (grant number 2016ZX08006002), one grant from the Department of Science and Technology of Guangdong Province, China (grant number 2018B030314004), and two grants from the Department of Agriculture and Rural Affairs of Guangdong Province, China (grant numbers 2019KJ26 and 2018ML1101).

\section{Author contribution statement}

Zheng Ao, Zicong Li, and Zhenfang Wu conceived and designed the experiments. Zheng Ao, Ting Gu, Junsong Shi performed the experiments. Zheng Ao and Ting Gu analyzed the data. Ting Gu, Junsong Shi, Enqin Zheng, and Gengyuan Cai contributed materials. Zheng Ao, Zicong Li, and Zhenfang Wu wrote and revised the paper.

\section{References}

Ahearne CE, Denihan NM, Walsh BH, Reinke SN, Kenny LC, Boylan GB, Broadhurst DI \& Murray DM 2016 Metabolite index and outcome in perinatal asphyxia and hypoxic-ischaemic encephalopathy. Neonatology 110 296-302. (https://doi.org/10.1159/000446556)

Ahmed M, Taylor W, Smith PR \& Becker MA 1999 Accelerated transcription of PRPS1 in X-linked overactivity of normal human phosphoribosylpyrophosphate synthetase. Journal of Biological Chemistry 274 7482-7488. (https://doi.org/10.1074/jbc.274.11.7482)

Ao Z, Li ZC, Wang XW, Zhao CF, Gan YM, Wu X, Zeng F, Shi JS, Gu T, Hong LJ et al. 2019 Identification of amniotic fluid metabolomic and placental transcriptomic changes associated with abnormal development of cloned pig fetuses. Molecular Reproduction and Development 86 278-291. (https://doi.org/10.1002/mrd.23102)

Ao Z, Liu DW, Zhao CF, Yue ZM, Shi JS, Zhou R, Cai GY, Zheng EG, Li ZC \& Wu ZF 2017 Birth weight, umbilical and placental traits in relation to neonatal loss in cloned pigs. Placenta 57 94-101. (https://doi. org/10.1016/j.placenta.2017.06.010)

Baxter EM, Jarvis S, D'Eath RB, Ross DW, Robson SK, Farish M, Nevison IM, Lawrence AB \& Edwards SA 2008 Investigating the behavioural and physiological indicators of neonatal survival in pigs. Theriogenology 69 773-783. (https://doi.org/10.1016/j.theriogenology.2007.12.007)

Borghi C, Rosei EA, Bardin T, Dawson J, Dominiczak A, Kielstein JT, Manolis AJ, Perez-Ruiz F \& Mancia G 2015 Serum uric acid and the risk of cardiovascular and renal disease. Journal of Hypertension 331729 1741. (https://doi.org/10.1097/HJH.0000000000000701)

Cao Z, Li Y, Chen Z, Wang H, Zhang M, Zhou N, Wu R, Ling Y, Fang F, Li N et al. 2015 Genome-wide dynamic profiling of histone methylation during nuclear transfer-mediated porcine somatic cell reprogramming. PLoS ONE 10 e0144897. (https://doi.org/10.1371/journal.pone.0144897)

Ceballos-Picot I, Mockel L, Potier MC, Dauphinot L, Shirley TL, ToreroIbad R, Fuchs J \& Jinnah HA 2009 Hypoxanthine-guanine phosphoribosyl transferase regulates early developmental programming of dopamine neurons: implications for Lesch-Nyhan disease pathogenesis. Human Molecular Genetics 18 2317-2327. (https://doi.org/10.1093/hmg/ ddp164)

Cedar H \& Bergman Y 2009 Linking DNA methylation and histone modification: patterns and paradigms. Nature Reviews Genetics 10 295-304. (https://doi.org/10.1038/nrg2540)

Dehghan A, van Hoek M, Sijbrands EJ, Hofman A \& Witteman JC 2008 High serum uric acid as a novel risk factor for type 2 diabetes. Diabetes Care 31 361-362. (https://doi.org/10.2337/dc07-1276)

Dhanasekaran S, Doherty TM, Kenneth J \& TB Trials Study Group 2010 Comparison of different standards for real-time PCR-based absolute quantification. Journal of Immunological Methods 354 34-39. (https:// doi.org/10.1016/j.jim.2010.01.004)

Estrada J, Sommer J, Collins B, Mir B, Martin A, York A, Petters RM \& Piedrahita JA 2007 Swine generated by somatic cell nuclear transfer have 
increased incidence of intrauterine growth restriction (IUGR). Cloning and Stem Cells 9 229-236. (https://doi.org/10.1089/clo.2006.0079)

Hobbs DJ, Steinke JM, Chung JY, Barletta GM \& Bunchman TE 2010 Rasburicase improves hyperuricemia in infants with acute kidney injury. Pediatric Nephrology 25 305-309. (https://doi.org/10.1007/s00467009-1352-1)

Hong LJ, Hou CY, Li XP, Li CC, Zhao SH \& Yu M 2014 Expression of heparanase is associated with breed-specific morphological characters of placental folded bilayer between Yorkshire and Meishan pigs. Biology of Reproduction 90 56. (https://doi.org/10.1095/biolreprod.113.114181)

Huan YJ, Hu K, Xie BT, Shi YQ, Wang F, Zhou Y, Liu SC, Huang B, Zhu J, Liu ZF et al. 2015 Ovulation statuses of surrogate gilts are associated with the efficiency of excellent pig cloning. PLOS ONE 10 e0142549. (https://doi.org/10.1371/journal.pone.0142549)

Inoue K, Kohda T, Sugimoto M, Sado T, Ogonuki N, Matoba S, Shiura H, Ikeda R, Mochida K, Fujii T et al. 2010 Impeding Xist expression from the active $X$ chromosome improves mouse somatic cell nuclear transfer. Science 330 496-499. (https://doi.org/10.1126/science.1194174)

Jiang L, Lai L, Samuel M, Prather RS, Yang X \& Tian XC 2008 Expression of $\mathrm{X}$-linked genes in deceased neonates and surviving cloned female piglets. Molecular Reproduction and Development 75 265-273. (https:// doi.org/10.1002/mrd.20758)

Jinnah HA, Visser JE, Harris JC, Verdu A, Larovere L, Ceballos-Picot I, Gonzalez-Alegre P, Neychev V, Torres RJ, Dulac O et al. 2006 Delineation of the motor disorder of Lesch-Nyhan disease. Brain 129 1201-1217. (https://doi.org/10.1093/brain/awl056)

Johnson CH, Ivanisevic J \& Siuzdak G 2016 Metabolomics: beyond biomarkers and towards mechanisms. Nature Reviews: Molecular Cell Biology 17 451-459. (https://doi.org/10.1038/nrm.2016.25)

Kanbay M, Ikizek M, Solak Y, Selcoki Y, Uysal S, Armutcu F, Eryonucu B, Covic A \& Johnson RJ 2011 Uric acid and pentraxin-3 levels are independently associated with coronary artery disease risk in patients with stage 2 and 3 kidney disease. American Journal of Nephrology 33 325-331. (https://doi.org/10.1159/000324916)

Kang DH, Nakagawa T, Feng L, Watanabe S, Han L, Mazzali M, Truong L, Harris R \& Johnson RJ 2002 A role for uric acid in the progression of renal disease. Journal of the American Society of Nephrology 13 2888-2897. (https://doi.org/10.1097/01.asn.0000034910.58454.fd)

Kataoka H, Yang K \& Rock KL 2015 The xanthine oxidase inhibitor febuxostat reduces tissue uric acid content and inhibits injury-induced inflammation in the liver and lung. European Journal of Pharmacology 746 174-179. (https://doi.org/10.1016/j.ejphar.2014.11.013)

Kurome M, Geistlinger L, Kessler B, Zakhartchenko V, Klymiuk N, Wuensch A, Richter A, Baehr A, Kraehe K, Burkhardt K et al. 2013 Factors influencing the efficiency of generating genetically engineered pigs by nuclear transfer: multi-factorial analysis of a large data set. BMC Biotechnology 13 43. (https://doi.org/10.1186/1472-6750-13-43)

Lapsia V, Johnson RJ, Dass B, Shimada M, Kambhampati G, Ejaz NI, Arif AA \& Ejaz AA 2012 Elevated uric acid increases the risk for acute kidney injury. American Journal of Medicine 125 302.e9-302.17. (https://doi.org/10.1016/j.amjmed.2011.06.021)

Maiuolo J, Oppedisano F, Gratteri S, Muscoli C \& Mollace V 2016 Regulation of uric acid metabolism and excretion. International Journal of Cardiology 213 8-14. (https://doi.org/10.1016/j. ijcard.2015.08.109)

Marincola FC, Dessi A, Pattumelli MG, Corbu S, Ossicini C, Ciccarelli S, Agostino R, Mussap M \& Fanos V 2015 1H NMR-based urine metabolic profile of IUGR, LGA, and AGA newborns in the first week of life. Clinica Chimica Acta 451 28-34. (https://doi.org/10.1016/j.cca.2015.08.008)

Mussap M, Antonucci R, Noto A \& Fanos V 2013 The role of metabolomics in neonatal and pediatric laboratory medicine. Clinica Chimica Acta $\mathbf{4 2 6}$ 127-138. (https://doi.org/10.1016/j.cca.2013.08.020)

Neychev VK \& Jinnah HA 2006 Sudden death in Lesch-Nyhan disease. Developmental Medicine and Child Neurology 48 923-926. (https://doi. org/10.1017/S0012162206002015)

Noto A, Fanos V \& Dessi A 2016 Metabolomics in newborns. Advances in Clinical Chemistry 74 35-61. (https://doi.org/10.1016/ bs.acc.2015.12.006)

Ogino K, Kato M, Furuse Y, Kinugasa Y, Ishida K, Osaki S, Kinugawa T, Igawa O, Hisatome I, Shigemasa C et al. 2010 Uric acid-lowering treatment with Benzbromarone in patients with heart failure: a double-blind placebo-controlled crossover preliminary study.
Circulation Heart Failure 3 73-81. (https://doi.org/10.1161/ CIRCHEARTFAILURE.109.868604)

Park J, Marjani SL, Lai L, Samuel M, Wax D, Davis SR, Bruno RS, Prather RS, Yang X \& Tian XC 2010 Altered gene expression profiles in the brain, kidney, and lung of deceased neonatal cloned pigs. Cellular Reprogramming 12 589-597. (https://doi.org/10.1089/cell.2010.0004)

Park JY, Kim JH, Choi YJ, Hwang KC, Cho SK, Park HH, Paik SS, Kim T, Park C, Lee HT et al. 2009 Comparative proteomic analysis of malformed umbilical cords from somatic cell nuclear transfer-derived piglets: implications for early postnatal death. BMC Genomics 10511. (https://doi.org/10.1186/1471-2164-10-511)

Park MR, Cho SK, Lee SY, Choi YJ, Park JY, Kwon DN, Son WJ, Paik SS, Kim T, Han YM \& Kim JH 2005 A rare and often unrecognized cerebromeningitis and hemodynamic disorder: a major cause of sudden death in somatic cell cloned piglets. Proteomics 5 1928-1939. (https:// doi.org/10.1002/pmic.200401079)

Perlstein TS, Gumieniak O, Williams GH, Sparrow D, Vokonas PS, Gaziano M, Weiss ST \& Litonjua AA 2006 Uric acid and the development of hypertension: the normative aging study. Hypertension $\mathbf{4 8}$ 1031-1036. (https://doi.org/10.1161/01.HYP.0000248752.08807.4c)

Psychogios N, Hau DD, Peng J, Guo AC, Mandal R, Bouatra S, Sinelnikov I, Krishnamurthy R, Eisner R, Gautam B et al. 2011 The human serum metabolome. PLOS ONE 6 e16957. (https://doi.org/10.1371/journal. pone.0016957)

Riches PL, Wright AF \& Ralston SH 2009 Recent insights into the pathogenesis of hyperuricaemia and gout. Human Molecular Genetics 18 R177-R184. (https://doi.org/10.1093/hmg/ddp369)

Rivera L, Siddaiah R, Oji-Mmuo C, Silveyra GR \& Silveyra P 2016 Biomarkers for bronchopulmonary dysplasia in the preterm infant. Frontiers in Pediatrics 4 33. (https://doi.org/10.3389/fped.2016.00033)

Ruan D, Peng J, Wang X, Ouyang Z, Zou Q, Yang Y, Chen F, Ge W, Wu H, Liu Z et al. 2018 XIST derepression in active X chromosome hinders pig somatic cell nuclear transfer. Stem Cell Reports 10 494-508. (https://doi. org/10.1016/j.stemcr.2017.12.015)

Ryu ES, Kim MJ, Shin HS, Jang YH, Choi HS, Jo I, Johnson RJ \& Kang DH 2013 Uric acid-induced phenotypic transition of renal tubular cells as a novel mechanism of chronic kidney disease. American Journal of Physiology: Renal Physiology 304 F471-F480. (https://doi.org/10.1152/ ajprenal.00560.2012)

Sautin YY \& Johnson RJ 2008 Uric acid: the oxidant-antioxidant paradox. Nucleosides, Nucleotides and Nucleic Acids 27 608-619. (https://doi. org/10.1080/15257770802138558)

Schmidt M, Winther KD, Secher JO \& Callesen H 2015 Postmortem findings in cloned and transgenic piglets dead before weaning. Theriogenology 84 1014-1023. (https://doi.org/10.1016/j.theriogenology.2015.05.037)

Siu YP, Leung KT, Tong MK \& Kwan TH 2006 Use of allopurinol in slowing the progression of renal disease through its ability to lower serum uric acid level. American Journal of Kidney Diseases 47 51-59. (https://doi. org/10.1053/j.ajkd.2005.10.006)

Vernon HJ 2015 Inborn errors of metabolism advances in diagnosis and therapy. JAMA Pediatrics 169 778-782. (https://doi.org/10.1001/ jamapediatrics.2015.0754)

Xie B, Zhang H, Wei R, Li Q, Weng X, Kong Q \& Liu Z 2016 Histone H3 lysine 27 trimethylation acts as an epigenetic barrier in porcine nuclear reprogramming. Reproduction 151 9-16. (https://doi.org/10.1530/REP15-0338)

Xu X, Hu J, Song N, Chen R, Zhang T \& Ding X 2017 Hyperuricemia increases the risk of acute kidney injury: a systematic review and metaanalysis. BMC Nephrology 18 27. (https://doi.org/10.1186/s12882-0160433-1)

Yamanaka K, Sugimura S, Wakai T, Kawahara M \& Sato E 2009 Acetylation level of histone $\mathrm{H} 3$ in early embryonic stages affects subsequent development of miniature pig somatic cell nuclear transfer embryos. Journal of Reproduction and Development 55 638-644. (https://doi. org/10.1262/jrd.20245)

Yang H \& Wu Z 2018 Genome editing of pigs for agriculture and biomedicine. Frontiers in Genetics 9 360. (https://doi.org/10.3389/ fgene.2018.00360)

Yelken B, Caliskan Y, Gorgulu N, Altun I, Yilmaz A, Yazici H, Oflaz H \& Yildiz A 2012 Reduction of uric acid levels with allopurinol treatment improves endothelial function in patients with chronic kidney disease. Clinical Nephrology 77 275-282. (https://doi.org/10.5414/cn107352) 
Yi L, Shi S, Wang Y, Huang W, Xia ZA, Xing Z, Peng W \& Wang Z 2016 Serum metabolic profiling reveals altered metabolic pathways in patients with post-traumatic cognitive impairments. Scientific Reports 621320. (https://doi.org/10.1038/srep21320)

Zhang A, Sun H, Wang P, Han Y \& Wang X 2012 Recent and potential developments of biofluid analyses in metabolomics. Journal of Proteomics 75 1079-1088. (https://doi.org/10.1016/j. jprot.2011.10.027)

Zhou N, Cao Z, Wu R, Liu X, Tao J, Chen Z, Song D, Han F, Li Y, Fang F et al. 2014 Dynamic changes of histone $\mathrm{H} 3$ lysine 27 acetylation in preimplantational pig embryos derived from somatic cell nuclear transfer. Animal Reproduction Science 148 153-163. (https://doi.org/10.1016/j. anireprosci.2014.06.002)
Zhou Y, Fang L, Jiang L, Wen P, Cao H, He W, Dai C \& Yang J 2012 Uric acid induces renal inflammation via activating tubular NF-kappaB signaling pathway. PLoS ONE 7 e39738. (https://doi.org/10.1371/ journal.pone.0039738)

Received 12 March 2020

First decision 29 April 2020

Revised manuscript received 6 May 2020

Accepted 14 May 2020 